\title{
Circulating resistin levels and risk of multiple myeloma in three prospective cohorts
}

Loredana Santo ${ }^{1}$, Lauren R Teras ${ }^{2}$, Graham G Giles ${ }^{3}$, Stephanie J Weinstein ${ }^{1}$, Demetrius Albanes ${ }^{1}$, Ye Wang ${ }^{4,5}$, Ruth M Pfeiffer ${ }^{1}$, Qing Lan ${ }^{1}$, Nathaniel Rothman ${ }^{1}$, Brenda M Birmann ${ }^{6,7}$, Graham A Colditz ${ }^{8,9}$, Michael N Pollak ${ }^{4,5}$, Mark P Purdue ${ }^{1}$ and Jonathan N Hofmann ${ }^{\star}, 1$

${ }^{1}$ Division of Cancer Epidemiology and Genetics, National Cancer Institute, Bethesda, MD 20892, USA; ${ }^{2}$ American Cancer Society, Atlanta, GA 30303, USA; ${ }^{3}$ Cancer Epidemiology Centre, Cancer Council Victoria, Melbourne, VIC 3004, Australia; ${ }^{4}$ Department of Oncology, McGill University, Montreal, QC H3T 1E2, Canada; ${ }^{5}$ Segal Cancer Centre, Jewish General Hospital, Montreal, QC H3T 1E2, Canada; ${ }^{6}$ Channing Division of Network Medicine, Department of Medicine, Brigham and Women's Hospital, Boston, MA 02115, USA; ${ }^{7}$ Department of Medicine, Harvard Medical School, Boston, MA 02115, USA; ${ }^{8}$ Department of Surgery and Alvin J. Siteman Cancer Center, Washington University School of Medicine and Barnes Jewish Hospital, St Louis, MO 63110, USA and ${ }^{9}$ Department of Epidemiology, Harvard TH Chan School of Public Health, Boston, MA 02115, USA

Background: Resistin is a polypeptide hormone secreted by adipose tissue. A prior hospital-based case-control study reported serum resistin levels to be inversely associated with risk of multiple myeloma (MM). To date, this association has not been investigated prospectively.

Methods: We measured resistin concentrations for pre-diagnosis peripheral blood samples from $178 \mathrm{MM}$ cases and 358 individually matched controls from three cohorts participating in the MM cohort consortium.

Results: In overall analyses, higher resistin levels were weakly associated with reduced MM risk. For men, we observed a statistically significant inverse association between resistin levels and MM (odds ratio, 0.44; 95\% confidence interval (Cl) $0.24-0.83$ and $0.54 ; 95 \% \mathrm{Cl} 0.29-0.99$, for the third and fourth quartiles, respectively, vs the lowest quartile; $\left.P_{\text {trend }}=0.03\right)$. No association was observed for women.

Conclusions: This study provides the first prospective evidence that low circulating resistin levels may be associated with an increased risk of MM, particularly for men.

Multiple myeloma (MM), a plasma cell disease, was newly diagnosed in an estimated 24280 individuals in 2016 in the United States (Teras et al, 2016). Besides well-established risk factors, such as male sex, older age, African ancestry, and a family history of haematological malignancies (Baris et al, 2013), obesity has been shown to increase MM risk (Teras et al, 2014). The association between obesity and MM may be attributable in part to altered levels of various adipokines (e.g., adiponectin, leptin, and resistin) secreted by adipose tissue (Dalamaga et al, 2009). We have recently shown that the risk of MM is increased for individuals with low pre-diagnosis circulating levels of adiponectin
(Hofmann et al, 2016), but not of leptin (Hofmann et al, 2012). The potential role of resistin in MM development is poorly understood. An increased risk of MM for individuals with low serum levels of resistin was observed by one small hospitalbased case-control study (73 MM cases and 73 controls) (Dalamaga et al, 2009). To our knowledge, the relationship between resistin and MM has not been evaluated prospectively. Using a nested case-control study involving three cohorts participating in the MM cohort consortium, we investigated whether pre-diagnosis circulating levels of resistin were associated with future MM risk.

*Correspondence: Dr JN Hofmann; E-mail: hofmannjn@mail.nih.gov

Received 31 January 2017; revised 11 July 2017; accepted 21 July 2017; published online 22 August 2017

(C) 2017 Cancer Research UK. All rights reserved 0007-0920/17 


\section{MATERIALS AND METHODS}

Cases $(n=178)$ and controls $(n=358)$ were selected from the Alpha-Tocopherol, Beta-Carotene Cancer Prevention Study (ATBC), the Cancer Prevention Study II (CPS-II), and the Melbourne Collaborative Cohort Study (MCCS) (ATBC, 1994; Calle et al, 2002; Giles and English, 2002). Participating cohorts received Institutional Review Board approval from their respective institutions. We selected cases with a primary incident diagnosis of MM (ICDA = 203; ICD-O-2-M =9731, 9732, and 9830; or ICD$\mathrm{O}-3-\mathrm{M}=9731-9734)$ and a stored blood sample collected $\geqslant 3$ months before MM diagnosis. Controls with no history of cancer were individually matched to cases based on cohort of origin, birth year ( \pm 12 months), sex, type of blood sample (serum, plasmaheparin, and plasma-EDTA), date of blood collection $( \pm 2$ months), and fasting status at blood draw with a $2: 1$ ratio as previously described (Birmann et al, 2012; Hofmann et al, 2016). All of the cases and controls included in this investigation were non-Hispanic whites.

Circulating levels of resistin were measured in duplicate by ELISA (Human Resistin Quantikine ELISA by R\&D Systems, Inc., Minneapolis, MN, USA). Assays were performed in the laboratory of MNP at McGill University. The lower limit of detection was $0.156 \mathrm{ng} \mathrm{ml}^{-1}$. Samples from MM patients and their matched controls were analysed in the same batch, and blinded quality control (QC) replicates were included in each batch as previously described (Hofmann et al, 2016). The overall intraclass correlation coefficient was 0.86 , and the coefficient of variation for pooled QC specimens was $6.1 \%$, with no evidence of laboratory drift across cohorts.

We used the Wilcoxon rank-sum test to assess differences in resistin levels between cases and controls. For our main analyses, we performed cohort- and sex-specific corrections of resistin values to reduce the impact of cohort-related variability, and to account for differences between men and women within and across the participating studies (Birmann et al, 2012; Hofmann et al, 2016) (Supplementary Methods). Odds ratios (ORs) and 95\% confidence intervals (95\% CIs) for risk of MM were computed using conditional logistic regression models with levels of resistin categorised into quartiles based on the distribution among controls. We performed analyses stratified by sex, time to MM diagnosis, and age at sample collection using conditional logistic regression models, and analyses stratified by BMI categories using unconditional logistic regression models adjusted for matching factors. Multiplicative interaction was assessed using Wald tests. Study-specific ORs and 95\% CIs were estimated comparing resistin levels above and below the median (based on the distribution in controls); we conducted a metaanalysis using both fixed and random effects models, and assessed heterogeneity across cohorts using the Cochran Q-test and the $I^{2}$ statistic. For all analyses, findings were considered statistically significant if the two-sided $P$-value was $<0.05$.

\section{RESULTS}

Cases and controls had similar distributions of sex, age at the blood draw, and type of blood sample (Table 1). Cohort- and sexcorrected resistin levels were somewhat lower among cases compared with controls; these differences were statistically significant among men $(P=0.006$, Wilcoxon rank-sum test $)$ but not among women $(P=0.22)$. Levels of resistin and total adiponectin (measured previously) were not correlated among cases or controls (Spearman's correlation coefficients of -0.07 and 0.09 , respectively; $P \geqslant 0.1$ ). In multivariate analyses of the pooled controls, circulating levels of resistin were higher among men compared with women, but were not associated with age or BMI (Supplementary Table S1).
Table 1. Selected characteristics of cases and controls

\begin{tabular}{|c|c|c|}
\hline Characteristic & Cases $^{a}$ & Controls ${ }^{a}$ \\
\hline Patients & $178(100)$ & $358(100)$ \\
\hline $\begin{array}{l}\text { Cohort } \\
\text { ATBC } \\
\text { CPS-II } \\
\text { MCCS }\end{array}$ & $\begin{array}{l}59(33.2) \\
67(37.6) \\
52(29.2)\end{array}$ & $\begin{array}{l}117(32.7) \\
135(37.7) \\
106(29.6)\end{array}$ \\
\hline $\begin{array}{l}\text { Sex } \\
\text { Female } \\
\text { Male }\end{array}$ & $\begin{array}{c}49(27.5) \\
129(72.5)\end{array}$ & $\begin{array}{l}100(27.9) \\
258(72.1)\end{array}$ \\
\hline Mean (s.d.) age at blood draw & $63.0(7.8)$ & $63.0(7.8)$ \\
\hline Mean (s.d.) BMl at blood draw, $\mathrm{kg} / \mathrm{m}^{2}$ & $26.9(4.0)$ & $26.5(4.2)$ \\
\hline $\begin{array}{l}\text { Type of blood sample } \\
\text { EDTA } \\
\text { Heparin plasma } \\
\text { Serum }\end{array}$ & $\begin{array}{l}67(37.6) \\
52(29.2) \\
59(33.2)\end{array}$ & $\begin{array}{l}135(37.7) \\
106(29.6) \\
117(32.7)\end{array}$ \\
\hline $\begin{array}{l}\text { Time from blood draw to diagnosis } \\
\quad<7 \text { years } \\
\geqslant 7 \text { years }\end{array}$ & $\begin{array}{l}85(47.8) \\
93(52.3)\end{array}$ & \\
\hline $\begin{array}{l}\text { Median resistin concentration' }{ }^{\mathbf{b}} \text { (IQR) } \\
\text { Overall } \\
\text { Female } \\
\text { Male }\end{array}$ & $\begin{array}{l}5.47(4.08-7.11) \\
6.24(5.11-8.44) \\
5.20(3.93-6.46)^{c}\end{array}$ & $\begin{array}{l}5.82(4.47-7.37) \\
5.88(4.48-7.66) \\
5.82(4.44-7.33)\end{array}$ \\
\hline \multicolumn{3}{|c|}{$\begin{array}{l}\text { Abbreviations: ATBC }=\text { Alpha-Tocopherol, Beta-Carotene Cancer Prevention Study; } \mathrm{BMI}= \\
\text { body mass index; CPS-II=the Cancer Prevention Study II; } I Q R=\text { interquartile range; } \\
M C C S=\text { Melbourne Collaborative Cohort Study. } \\
{ }^{2} \text { Reported as } N(\%) \text { unless otherwise noted. } \\
{ }^{b} \text { On the basis of corrected resistin levels in } \mathrm{ng} \mathrm{ml}^{-1} \text { (Supplementary Methods). } \\
{ }^{c} \text { Wilcoxon two-sample test } P=0.006 \text {. }\end{array}$} \\
\hline
\end{tabular}

Higher resistin levels were weakly associated with a reduced risk of MM in overall analyses, although the observed associations were not statistically significant (Table 2). Findings were similar after adjusting for BMI and adiponectin levels. Among a subset of participants from the ATBC and MCCS cohorts with available data on markers related to IGF-1 and interleukin (IL)-6 pathways (Birmann et al, 2012), we found that results were essentially unchanged after adjustment for these other analytes (data not shown). Among men, we observed a statistically significant reduced risk of $\mathrm{MM}$ among those with higher levels of resistin (ORs of 0.44 (95\% CI 0.24-0.83) and $0.54(0.29-0.99)$ for the third and fourth quartiles, respectively, $v s$ the lowest quartile; $\left.P_{\text {trend }}=0.026\right)$. This association remained after adjusting for BMI and adiponectin levels (data not shown). In contrast, resistin levels were not associated with $\mathrm{MM}$ risk among women $\left(P_{\text {interaction }}=0.12\right)$. In other stratified analyses, we did not observe statistically significant differences in the ORs across strata for time to $\mathrm{MM}$ diagnosis, BMI category, or age at blood collection. Our main findings were essentially unchanged after excluding high outlying resistin levels and when quartiles were based on the overall distribution of resistin levels among controls rather than the cohort- and sex-corrected levels.

Cohort- and sex-specific results are shown in Figure 1. Among men, there was some evidence of heterogeneity across cohorts $\left(I^{2}=62.3 \%, P=0.071\right)$. The association was strongest among men in the MCCS (OR 0.12, 95\% CI 0.026-0.53), although nonsignificant inverse associations were also observed among men in the other cohorts (ORs of $0.63(0.30-1.34)$ and $0.79(0.42-1.48)$ in CPS-II and ATBC, respectively). Among women, ORs were elevated but not statistically significant in both CPS-II and MCCS.

\section{DISCUSSION}

This study is, to our knowledge, the first prospective investigation of circulating levels of resistin and risk of MM. Our findings 
Table 2. Circulating resistin levels and risk of MM, overall and stratified by selected characteristics

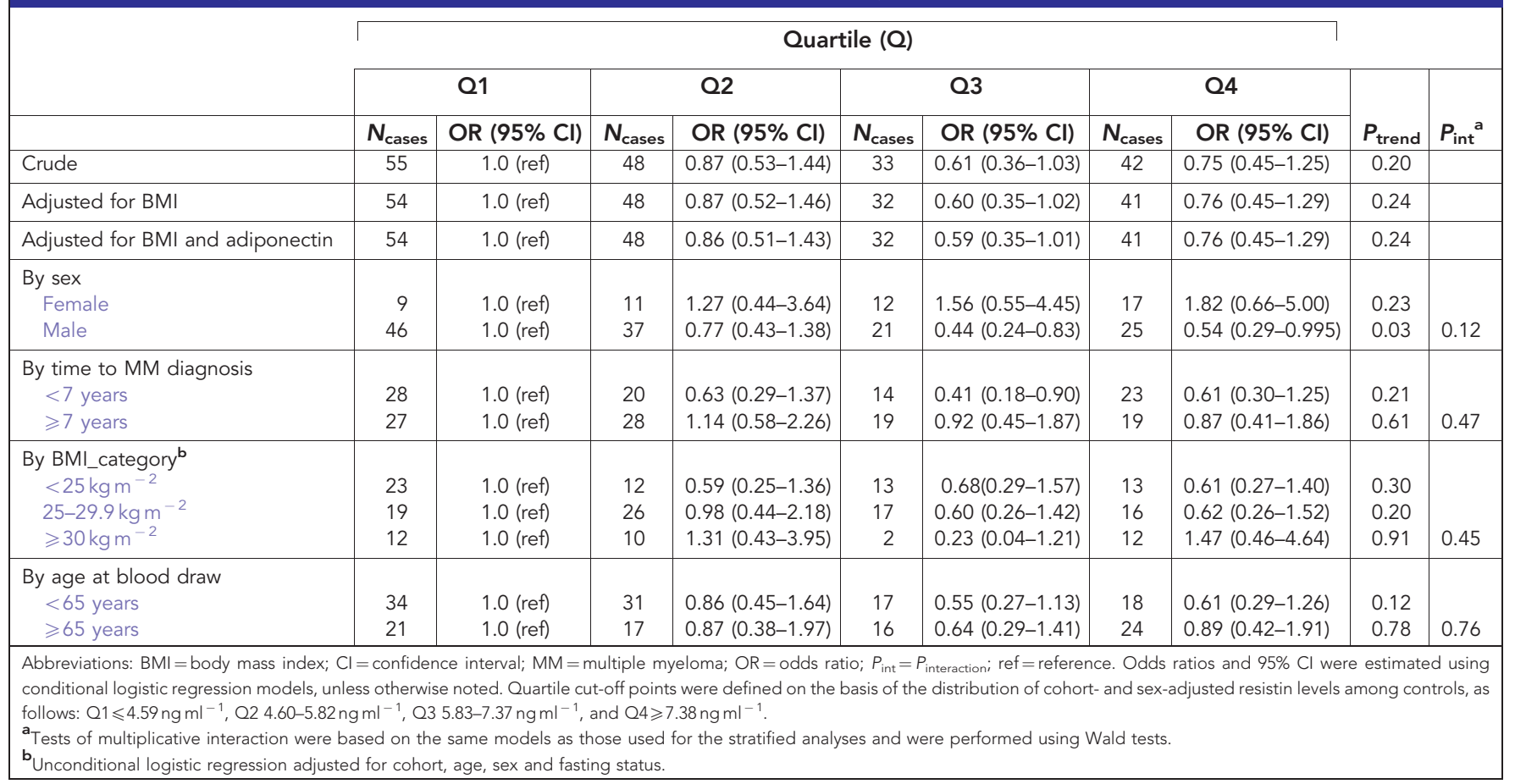

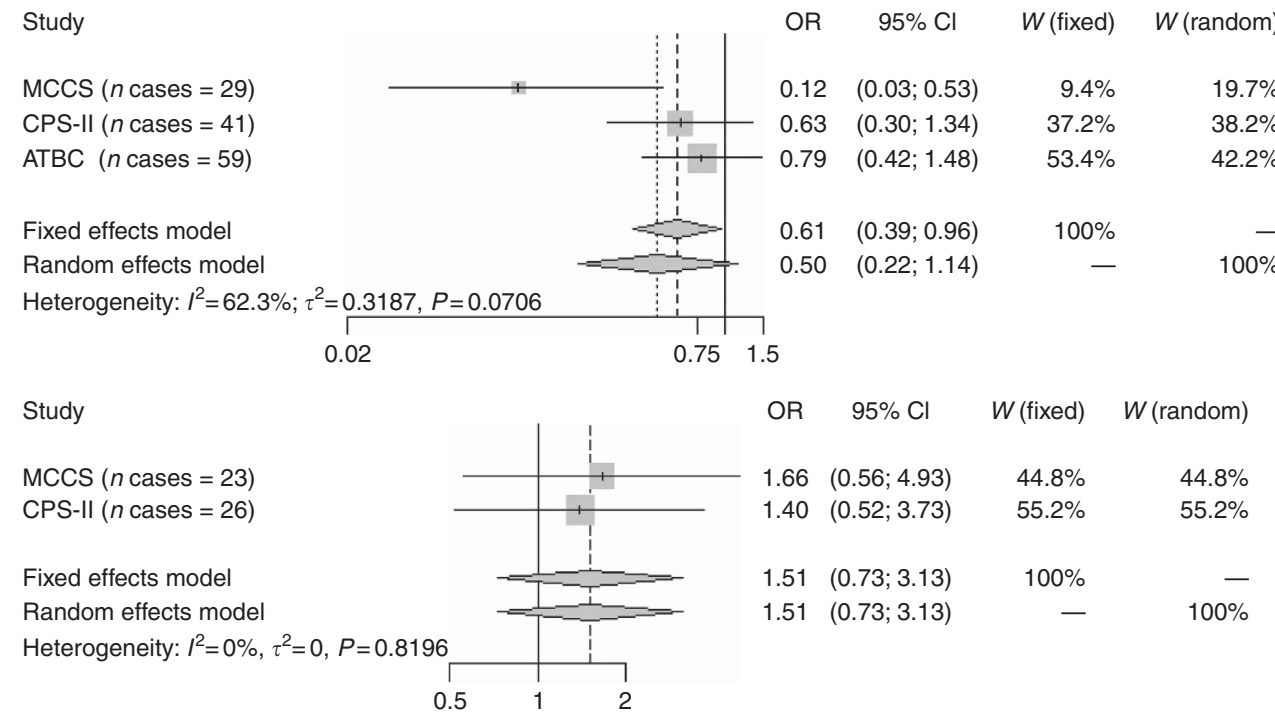

Figure 1. Cohort-specific and meta-analysis summary ORs and $95 \% \mathrm{Cls}$ for the association between circulating resistin levels (above vs below the median) and MM risk among men (upper panel) and women (lower panel).

suggest that high pre-diagnosis circulating resistin levels are associated with a reduced future risk of MM development, in particular among men. These results are consistent with findings from a prior hospital-based case-control study (Dalamaga et al, 2009). Although we did not find evidence of an association among women, our investigation included relatively few female MM cases and thus we had limited statistical power for this subgroup analysis. Our findings may also reflect true differences by sex in the biological activity of resistin due to interaction with sex or metabolic hormones or other inflammatory markers that are differentially expressed in men and women (Dalamaga et al, 2013). We also observed a somewhat stronger association during the time period closer to MM diagnosis, which may reflect altered resistin expression related to onset or progression of monoclonal gammopathy of undetermined significance.

Resistin increases nuclear factor kappa B-related monocyte expression of pro-inflammatory cytokines such as IL-6 (Tilg and Moschen, 2006; Lee et al, 2014). Thus, the observed increased risk of $\mathrm{MM}$ in males with lower levels of resistin might reflect a compensatory effect of resistin or a negative feedback loop following the production of IL-6 and/or other cytokines with known effects on proliferation and survival of MM cells (Dalamaga et al, 2009). Alternatively, previous studies have shown that TNF- $\alpha$ 
decreases resistin secretion in murine models (Rajala et al, 2002). If TNF- $\alpha$, a well-characterised pro-inflammatory cytokine that stimulates MM cell proliferation (Hideshima et al, 2001), also acts as a negative regulator of resistin in humans, this action may explain the observed inverse association between pre-diagnosis resistin levels and MM risk. This hypothesis is corroborated by increased resistin levels in $\mathrm{MM}$ patients after treatment with thalidomide, a TNF- $\alpha$ inhibitor (Reseland et al, 2009).

Resistin deregulation in obesity-related inflammatory conditions may also result from altered expression by non-adipocyte inflammatory cells, such as macrophages, in adipose tissue (Patel et al, 2003; Curat et al, 2006). While some studies have observed elevated levels of resistin among individuals with higher BMI or visceral fat area (Yannakoulia et al, 2003; Reseland et al, 2009), other studies found no association (Lee et al, 2003; Dalamaga et al, 2013). The lack of association of resistin with BMI in our study suggests that resistin may influence $M M$ risk through other inflammatory processes. Notably, resistin is also highly expressed in the bone marrow (BM) where it is secreted by osteoclasts and osteoblasts, as well as by monocytes and macrophages (Patel et al, 2003). Resistin activates osteoclastogenesis and promotes osteoblast proliferation (Thommesen et al, 2006), which suggests a role for resistin in bone remodelling. Considering the interplay between the BM microenvironment and the proliferation of MM cells (Eda et al, 2016), impaired resistin expression in the BM niche may induce changes that are favourable to the proliferation of MM cells, which might explain the observed inverse association between resistin and MM risk. Functional analyses in BM tissue could help to clarify the role of resistin and other adipokines in MM pathogenesis.

The strengths of our study include its prospective design and the pooling of data across three cohorts. Limitations include the lack of detailed information on clinical characteristics of MM at diagnosis, as well as information on family history of lymphohaematopoietic malignancies. Given that having a family history of these relatively rare malignancies is uncommon in the general population (Schinasi et al, 2016), the potential for confounding by family history is likely to be minimal. However, further investigation in family-based studies and other studies with detailed clinical records may be informative. Finally, although this study is the largest to date that has evaluated the association between resistin and MM, we had limited statistical power for analyses restricted to women, as well as for the cohort-specific and other stratified analyses. Extending this investigation to other prospective cohorts is required to confirm our findings and to better elucidate the differences by sex in the relationship between resistin and MM.

\section{ACKNOWLEDGEMENTS}

This work was supported by the Intramural Research Program of the National Institutes of Health, National Cancer Institute. The American Cancer Society funds the creation, maintenance, and updating of the Cancer Prevention Study-II cohort. MNP's laboratory is funded in part by a grant from the Terry Fox Foundation, Vancouver, Canada. The ATBC Study is supported by the Intramural Research Program of the U.S. National Cancer Institute, National Institutes of Health, and by U.S. Public Health Service contract HHSN261201500005C from the National Cancer Institute, Department of Health and Human Services. The MMCC was first established in part with funds from NIH/NCI extramural grants K07 CA115687 (BMB) and R01 CA127435 in addition to the aforementioned support from the NCI Intramural Research Program. BMB is currently supported in part by R21 CA198239.

\section{CONFLICT OF INTEREST}

The authors declare no conflict of interest.

\section{REFERENCES}

ATBC (1994) The alpha-tocopherol, beta-carotene lung cancer prevention study: design, methods, participant characteristics, and compliance. The ATBC Cancer Prevention Study Group. Ann Epidemiol 4(1): 1-10.

Baris D, Brown L, Andreotti G, Devesa S (2013) Epidemiology of multiple myeloma. In: Wiernik P, Goldman J, Dutcher J, Kyle R (eds). Neoplastic Disease of the Blood. 5th edn. Springer: New York, NY, USA, pp 547-563.

Birmann BM, Neuhouser ML, Rosner B, Albanes D, Buring JE, Giles GG, Lan Q, Lee IM, Purdue MP, Rothman N, Severi G, Yuan JM, Anderson KC, Pollak M, Rifai N, Hartge P, Landgren O, Lessin L, Virtamo J, Wallace RB, Manson JE, Colditz GA (2012) Prediagnosis biomarkers of insulin-like growth factor-1, insulin, and interleukin-6 dysregulation and multiple myeloma risk in the Multiple Myeloma Cohort Consortium. Blood 120(25): 4929-4937.

Calle EE, Rodriguez C, Jacobs EJ, Almon ML, Chao A, McCullough ML, Feigelson HS, Thun MJ (2002) The American Cancer Society Cancer Prevention Study II Nutrition Cohort: rationale, study design, and baseline characteristics. Cancer 94(9): 2490-2501.

Curat CA, Wegner V, Sengenes C, Miranville A, Tonus C, Busse R, Bouloumie A (2006) Macrophages in human visceral adipose tissue: increased accumulation in obesity and a source of resistin and visfatin. Diabetologia 49(4): 744-747.

Dalamaga M, Karmaniolas K, Panagiotou A, Hsi A, Chamberland J, Dimas C, Lekka A, Mantzoros CS (2009) Low circulating adiponectin and resistin, but not leptin, levels are associated with multiple myeloma risk: a case-control study. Cancer Causes Control 20(2): 193-199.

Dalamaga M, Sotiropoulos G, Karmaniolas K, Pelekanos N, Papadavid E, Lekka A (2013) Serum resistin: a biomarker of breast cancer in postmenopausal women? Association with clinicopathological characteristics, tumor markers, inflammatory and metabolic parameters. Clin Biochem 46(7-8): 584-590.

Eda H, Santo L, David Roodman G, Raje N (2016) Bone disease in multiple myeloma. Cancer Treat Res 169: 251-270.

Giles GG, English DR (2002) The Melbourne Collaborative Cohort Study. IARC Sci Publ 156: 69-70.

Hideshima T, Chauhan D, Schlossman R, Richardson P, Anderson KC (2001) The role of tumor necrosis factor alpha in the pathophysiology of human multiple myeloma: therapeutic applications. Oncogene 20(33): 4519-4527.

Hofmann JN, Birmann BM, Teras LR, Pfeiffer RM, Wang Y, Albanes D, Baris D, Colditz GA, De Roos AJ, Giles GG, Hosgood HD, Lan Q, Landgren O, Liao LM, Rothman N, Weinstein SJ, Pollak MN, Neuhouser ML, Purdue MP (2016) Low levels of circulating adiponectin are associated with multiple myeloma risk in overweight and obese individuals. Cancer Res 76(7): 1935-1941.

Hofmann JN, Liao LM, Pollak MN, Wang Y, Pfeiffer RM, Baris D, Andreotti G, Lan Q, Landgren O, Rothman N, Purdue MP (2012) A prospective study of circulating adipokine levels and risk of multiple myeloma. Blood 120(22): 4418-4420.

Lee JH, Chan JL, Yiannakouris N, Kontogianni M, Estrada E, Seip R, Orlova C, Mantzoros CS (2003) Circulating resistin levels are not associated with obesity or insulin resistance in humans and are not regulated by fasting or leptin administration: cross-sectional and interventional studies in normal, insulin-resistant, and diabetic subjects. J Clin Endocrinol Metab 88(10): 4848-4856.

Lee S, Lee HC, Kwon YW, Lee SE, Cho Y, Kim J, Lee S, Kim JY, Lee J, Yang HM, Mook-Jung I, Nam KY, Chung J, Lazar MA, Kim HS (2014) Adenylyl cyclase-associated protein 1 is a receptor for human resistin and mediates inflammatory actions of human monocytes. Cell Metab 19(3): 484-497.

Patel L, Buckels AC, Kinghorn IJ, Murdock PR, Holbrook JD, Plumpton C, Macphee CH, Smith SA (2003) Resistin is expressed in human macrophages and directly regulated by PPAR gamma activators. Biochem Biophys Res Commun 300(2): 472-476.

Rajala MW, Lin Y, Ranalletta M, Yang XM, Qian H, Gingerich R, Barzilai N, Scherer PE (2002) Cell type-specific expression and coregulation of 
murine resistin and resistin-like molecule-alpha in adipose tissue. $\mathrm{Mol}$ Endocrinol 16(8): 1920-1930.

Reseland JE, Reppe S, Olstad OK, Hjorth-Hansen H, Brenne AT, Syversen U, Waage A, Iversen PO (2009) Abnormal adipokine levels and

leptin-induced changes in gene expression profiles in multiple myeloma. Eur J Haematol 83(5): 460-470.

Schinasi LH, Brown EE, Camp NJ, Wang SS, Hofmann JN, Chiu BC, Miligi L, Beane Freeman LE, de Sanjose S, Bernstein L, Monnereau A, Clavel J,

Tricot GJ, Atanackovic D, Cocco P, Orsi L, Dosman JA, McLaughlin JR, Purdue MP, Cozen W, Spinelli JJ, de Roos AJ (2016) Multiple myeloma and family history of lymphohaematopoietic cancers: results from the International Multiple Myeloma Consortium. Br J Haematol 175(1): 87-101.

Teras LR, DeSantis CE, Cerhan JR, Morton LM, Jemal A, Flowers CR (2016) 2016 US lymphoid malignancy statistics by World Health Organization subtypes. CA Cancer J Clin 66: 443-459.

Teras LR, Kitahara CM, Birmann BM, Hartge PA, Wang SS, Robien K, Patel AV, Adami HO, Weiderpass E, Giles GG, Singh PN, Alavanja M, Beane Freeman LE, Bernstein L, Buring JE, Colditz GA, Fraser GE, Gapstur SM, Gaziano JM, Giovannucci E, Hofmann JN, Linet MS, Neta G, Park Y, Peters U, Rosenberg PS, Schairer C, Sesso HD, Stampfer MJ,
Visvanathan K, White E, Wolk A, Zeleniuch-Jacquotte A, de Gonzalez AB, Purdue MP (2014) Body size and multiple myeloma mortality: a pooled analysis of 20 prospective studies. Br J Haematol 166(5): 667-676.

Thommesen L, Stunes AK, Monjo M, Grosvik K, Tamburstuen MV, Kjobli E, Lyngstadaas SP, Reseland JE, Syversen U (2006) Expression and regulation of resistin in osteoblasts and osteoclasts indicate a role in bone metabolism. J Cell Biochem 99(3): 824-834.

Tilg H, Moschen AR (2006) Adipocytokines: mediators linking adipose tissue, inflammation and immunity. Nat Rev Immunol 6(10): 772-783.

Yannakoulia M, Yiannakouris N, Bluher S, Matalas AL, Klimis-Zacas D, Mantzoros CS (2003) Body fat mass and macronutrient intake in relation to circulating soluble leptin receptor, free leptin index, adiponectin, and resistin concentrations in healthy humans. J Clin Endocrinol Metab 88(4): $1730-1736$.

This work is published under the standard license to publish agreement. After 12 months the work will become freely available and the license terms will switch to a Creative Commons AttributionNonCommercial-Share Alike 4.0 Unported License.

Supplementary Information accompanies this paper on British Journal of Cancer website (http://www.nature.com/bjc) 